\title{
Lymphocyte reactivity of workers exposed to carcinogenic and non-carcinogenic chemicals
}

\author{
S KUMAR, ${ }^{1}$ G TAYLOR, ${ }^{2}$ WENDY HURST, ${ }^{1}$ P WILSON, ${ }^{1}$ AND C B COSTELLO ${ }^{3}$ \\ From the Department of Bacteriology and Virology, ${ }^{1}$ The University, Manchester, UK, the Medical Centre, ${ }^{2}$ \\ Wausau, Wisconsin 54401, USA, and Salford Royal Hospital, ${ }^{3}$ Salford, UK
}

ABSTRACT Immunological studies have shown an increased lymphocyte reactivity in patients with early stage bladder cancer and individuals with pre-stage-T 1 exposed to bladder carcinogens (2-naphthylamine and industrial 1-naphthylamine containing 4-8\% 2-naphthylamine) before 1952that is, those at high risk of developing bladder cancer. Because of the close chemical similarity of Tobias acid (2-naphthylamine-1 sulphonic acid) to 2-naphthylamine, the lymphocytotoxicity of workers exposed to this chemical was investigated. The results show that the workers using Tobias acid unlike those exposed to 2-naphthylamine have lymphocytes with a normal range of reactivity towards bladder cancer cells, which is in keeping with the suggestion that Tobias acid is noncarcinogenic. The probable reason for its non-carcinogenicity is that the relatively very large size and hydrophilic properties of the sulphonic acid group prevents enzymic action on the amino group by steric hindrance. The present lymphocytotoxicity results strengthens our earlier conclusion that the observed increased lymphocyte reactivity in workers exposed to bladder carcinogens is specific.

Bladder cancer was first suspected as an occupational hazard in 1895 after Rehn ${ }^{1}$ observed three cases from a single factory making magenta dye. At the time the cause was wrongly attributed to aniline. Over the years, as the dyestuffs industry expanded, an increasing number of cases of bladder tumours were reported among workers producing aromatic amines. Case $e t a l^{2}$ found that in one factory the mortality rate from bladder cancer was at least 30 times higher than in the normal male population of England and Wales. The work of Scott ${ }^{3}$ and Case et $a l^{2}$ incriminated three chemicals, 2-naphthylamine (beta), 1-naphthylamine (alpha), and benzidine as potential bladder carcinogens. Commercial 1naphthylamine contained up to $8 \%$ 2-naphthylamine and the latter was considered to be entirely responsible for its carcinogenic activity. Another chemical, 4-aminobiphenyl was also found to be a potent bladder carcinogen. ${ }^{4}$ The manufacture of these materials in Britain was prohibited by 1967 . Tobias acid (2-naphthylamine 1-sulphonic acid), which chemically is similar to 2-naphthylamine, is being commercially used as an intermediate in the manufacture of a wide variety of dyestuffs.

Koss $^{5} 5$ used the standard exfoliative cytology

Received 31 March 1980

Accepted 2 May 1980 originally developed by Papanicolaou and identified the majority of bladder tumours to have resulted from exposure to 4-aminobiphenyl. Cytological evaluation of the urine sediment, however, proved to be of less value in diagnosing low grade papillary tumours. The limitations of Papanicolaou staining of urinary sediments in identifying cellular abnormalities among workers exposed to bladder carcinogens have been well recognised. ${ }^{7}$

Recent immunological studies have shown an increased lymphocytotoxicity to bladder cancer cells in patients with bladder cancer. ${ }^{8-12}$ It has been further reported that specific lymphocytotoxicity is related to the stage of the disease, with a higher proportion of early-stage patients (T1 and $\mathrm{T} 2$ ) showing increases compared to late-stage (T3 and T4). ${ }^{10}$ Our own lymphocytotoxicity studies 1314 have shown increased reactivity in lymphocytes, not only from patients with early-stage bladder cancer, but also from pre-stage-T 1 individuals (exposed before 1952 to 1- and 2-naphthylamine and benzidine)-that is, those considered to be at high risk of developing bladder cancer but who have no detectable evidence of the disease. Because of the chemical similarity of Tobias acid to 2-naphthylamine we have investigated the lymphocyte reactivity against bladder cancer cells of workers exposed to this substance, 
Table 1 Details of 70 workers exposed to naphthylamine and 19 workers exposed to Tobias acid

\begin{tabular}{lll}
\hline & $\begin{array}{l}\text { Naphthylamine } \\
\text { workers }\end{array}$ & $\begin{array}{l}\text { Tobias acid } \\
\text { workers }\end{array}$ \\
\hline Mean age on assay (yr) & $62.6 \pm 5.6$ & $44.0 \pm 10.6$ \\
$\begin{array}{l}\text { Mean age on first } \\
\text { exposure (yr) }\end{array}$ & $28.6 \pm 7.7$ & $35.2 \pm 9.9$ \\
$\begin{array}{l}\text { Mean duration of } \\
\text { exposure (yr) }\end{array}$ & $3.6 \pm 6.2$ & $6.5 \pm 5.7$ \\
\hline
\end{tabular}

\section{Materials and methods}

\section{INDIVIDUALS STUDIED}

Tobias acidgroup-Nineteen male workers exposed to Tobias acid (table 1).

Naphthylamine group-Seventy male workers with no detectable bladder cancer exposed to either pure naphthylamine (2-NA) or 1-naphthylamine, or both, containing 4-8\% 2-naphthylamine before 1952.

Bladder cancer group-Twenty-three untreated patients with transitional cell cancer of the bladder. There were 19 men and 4 women; 19 were in clinical stage I, two in stage II, and two in stage III. Six of the 19 male patients had been employed in industries in which there was potential exposure to known carcinogens.

Normal donors-Forty-two adult healthy male blood donors with no known exposure to bladder or other carcinogens.

Peripheral blood lymphocytes from the above four groups were separated following the procedure published recently. ${ }^{13}$

Lymphocytotoxicity test-The details of the test were reported recently. ${ }^{13}$ Briefly, the ability of separated peripheral blood lymphocytes to kill bladder cancer target cells was measured in a reproducible manner. The results are expressed as numbers of lymphocytes required to kill $50 \%$ of standard number of target cells. This number, $\mathbf{L D}_{50}$, is thus high if the lymphocyte reactivity of an individual worker is low, conversely low if reactivity is high. ${ }^{14}$

\section{Results}

Application of the Kruskal Wallis test using all four groups indicated that the results of at least one of the groups differed significantly from the rest $(\mathrm{p}<0.001)$. Analysis by the Mann-Whitney $U$ test showed that there was no significant difference in lymphocyte reactivity between the naphthylamine workers and the patient with bladder cancer $(\mathrm{p}>$ 0.05 ), although they were significantly different to normal blood donors $(p<0.001)$. Tobias acid workers, however, were significantly different from naphthylamine workers $(\mathrm{p}<0.01)$ and patients with bladder cancer $(p<0.05)$, but were not significantly different from normal blood donors $(p>0.05)$. These differences are reflected in the median values as shown in table 2. The interquartile range for Tobias acid workers is almost identical with that of normal blood donors, whereas the range for patients with bladder cancer and naphthylamine workers is much narrower and lower, indicating greater lymphocyte reactivity by these two groups.

In addition, our data were analysed to examine if differences in the mean ages of the four groups investigated could have influenced lymphocytotoxicity. The age had no effect whatsoever on lymphocytotoxicity (our unpublished data).

\section{Discussion}

Tobias acid workers, unlike those exposed to 2-NA, have lymphocytes with a normal range of reactivity towards bladder cancer cells. This is in keeping with the suggestion that Tobias acid is non-carcinogenic despite its similarity to 2-NA. Theoretically, two different mechanisms of biotransformation of Tobias acid into carcinogenic metabolite are possible. Firstly, it may be desulphonated to give 2-NA. Secondly, the amino group of Tobias acid may be oxidised to give hydroxylamine as in the accepted mechanism of carcinogenicity of 2-NA that entails oxidation of amino groups to give 2-naphthylhydroxylamine. So far as we are aware carcinogenicity bioassays have not been carried out in dogs

Table 2 Lymphocytotoxicity results using bladder tumour cells

\begin{tabular}{lllll}
\hline & Normal donors & Patients with bladder cancer & Naphthylamine workers & Tobias acid workers \\
\hline Median LD so & 481 & 204 & 221 & 365 \\
Interquartiles & $246-5000$ & $88-603$ & $121-374$ & $250-5000$ \\
Group size & 42 & 23 & 70 & 19
\end{tabular}

Kruskal Wallis test: Null hypothesis that the four groups have similar data distribution is rejected $\mathbf{p}<0.001$.

Mann-Whitney U test: Normal donors $v$ patients with bladder cancer, significant difference $p<0.01$; normal donor $v$ naphthylamine groups, significant difference $\mathrm{p}<0.001$; normal donor $\mathrm{v}$ Tobias acid workers, no difference $\mathrm{p}>0.05$; patients with bladder cancer $\mathrm{v}$ naphthylamine group, no difference $\mathrm{p}>0.05$; patients with bladder cancer $\mathrm{v}$ Tobias acid workers, significant difference $p<0.05$; Tobias acid workers $v$ naphthylamine group, significant difference $\mathbf{p}<0.01$. 
(the only suitable model for human bladder cancer), but the metabolic studies of P L Batten (personal communication), who fed dogs with Tobias acid, have shown that the acid is readily absorbed and excreted by the dog. The 2-NA concentration in the urine of treated and control dogs were similar; furthermore an $\mathrm{N}$-hydroxy metabolite was not detected in the urine of the test dogs. Batten suggested that the lack of carcinogenic activity of Tobias acid might be due to the relatively very large size and hydrophilic properties of the sulphonic acid group, which prevents any enzymic action on the amino group by steric hindrance.

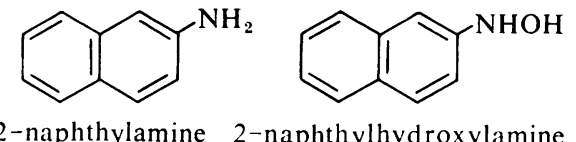<smiles>Nc1ccc2ccccc2c1S(=O)(=O)O</smiles>

Tobias acid

The present results also strengthen our earlier conclusions that the observed increased lymphocyte reactivity in workers exposed to bladder carcinogens is specific as the workers exposed to chemically similar, but non-carcinogenic, substances do not show this increased lymphocyte reactivity towards bladder cancer cells.

This study would not have been possible without the much appreciated co-operation of Drs J S Gardiner, G H Shaw, A E J Evans, and W G Taylor, medical department, organics division, ICI Ltd. We would like to acknowledge our deep gratitude to Sister A I Underwood and Sister J M Boyne for their help in the collection of many specimens.

\section{References}

${ }^{1}$ Rehn L. Über Blasenerkrankungen bei Fuchsin-arbeitern. Archiv für Klinische Chirurgie 1895;50:588-600.

${ }^{2}$ Case RAM, Hosker MW, McDonald DB, Pearson JT. Tumours of the urinary bladder in workers engaged in the manufacture and use of certain dyestuff intermediates in the British chemical industry. I The role of aniline, benzidine, alpha-naphthylamine and betanaphthylamine $\mathrm{Br} J$ Ind Med 1954;11:75-104.

${ }^{3}$ Scott TS. Carcinogenic and chronic toxic hazards of aromatic amines. Amsterdam: Elsevier, 1962:46-74.

${ }^{4}$ Melick WF, Escue HM, Naryka JJ, Mezera RA, Wheeler EP. The first reported cases of human bladder tumours due to carcinogen xenylamine. J Urol 1955;74:760-6.

${ }^{5}$ Koss LG. Diagnostic cytology and its histopathologic bases. 2nd ed. Philadelphia: JB Lippincott, 1968:409-52.

${ }^{6}$ Koss LG. Cytology in the diagnosis of bladder cancer. In: Cooper EH, Williams RE, eds. The biology and clinical management of bladder cancer. Leeds: Blackwell Scientific Publications, 1975:111-40.

7 Zavori MR, Horgg U, Bingham E. Benzidine exposure as a cause of bladder tumours. Arch Environ Health 1973; 27:1-7.

${ }^{8}$ Bubenik J, Perlmann P, Helmstein K, Moberger G. Cellular and immune urinary bladder carcinomas. Int J Cancer 1970;5:310-9.

${ }^{9}$ Bubenik J, Perlmann P, Helmstein K, Moberger G. Immune response to urinary bladder tumour in man. Int J Cancer 1970;5:39-46.

10 O'Toole C, Perlmann P, Unsgaard B, Morberger G, Edsmyr $\mathrm{F}$. Cellular immunity to human urinary bladder carcinomas. 1 Correlation to clinical stage and radiotherapy. Int J Cancer 1972;10:77-91.

${ }^{11}$ O'Toole C, Perlmann P, Wigzell H, Unsgaard B, Letterlund CG. Lymphocyte cytotoxicity in bladder cancer. No requirements for thymus-derived effector sells? Lancet 1973 ; $:$ :1085-8.

12 Troye M, Villien M, Gape GR, Perlmann P. Cytotoxicity in vitro of blood lymphocytes from bladder cancer patients and controls to allogenic or autologous tumour cells derived from established cell lines or short-term cultures. Int J Cancer 1980:25:33-43.

13 Taylor G, Kumar S, Brenchley P, Costello B, Shaw GH. Immunosurveillance in premalignant occupational bladder disease. Int $J$ Cancer 1979;23:287-93.

${ }^{14}$ Kumar S, Taylor G, Wilson P, Hurst W. Prognostic significance of specific immunoreactivity in occupational bladder cancer. $\mathrm{Br} \mathrm{MedJ}$ 1980;280:512-3. 